\title{
Relation between atrioventricular pathways and ventricular response during atrial fibrillation and flutter ${ }^{\star}$
}

\author{
EDWARD ROWLAND, PAUL CURRY, + KIM FOX, DENNIS KRIKLER
}

From the Division of Cardiovascular Disease, Royal Postgraduate Medical School, Hammersmith Hospital, London

SUMMARY We have analysed the ventricular response as seen on the surface electrocardiogram in patients with paroxysmal atrial fibrillation and flutter in relation to the electrophysiological properties of the corresponding atrioventricular pathways. In 15 patients who had atrial fibrillation with conduction solely through the atrioventricular node, there was a significant correlation between the shortest and mean RR intervals during atrial fibrillation and the functional refractory period, "pre-Wenckebach cycle length", and the shortest ventricular cycle length that resulted from 1:1 atrioventricular conduction. In 18 patients with conduction through an accessory atrioventricular pathway the only good correlation was between the shortest and mean ventricular rate during atrial fibrillation and the "pre-Wenckebach cycle length" and shortest ventricular cycle length during 1:1 atrioventricular conduction. In 12 patients with an atriofascicular bypass tract or rapidly conducting atrioventricular node there was no significant correlation between the RR intervals during atrial fibrillation and the electrophysiological indices; the same lack of correlation was evident in all 11 patients with atrial flutter, all of whom had atrioventricular nodal conduction.

The response of atrioventricular pathways to electrophysiological testing, particularly the use of incremental atrial pacing, provides useful guidance in the further management of these atrial arrhythmias.

There has been considerable interest in paroxysmal atrial fibrillation complicating the Wolff-ParkinsonWhite syndrome because of the risk of sudden death, ${ }^{12}$ but less attention has been paid to the electrophysiological consequences of this arrhythmia in the presence of normal atrioventricular nodal conduction. The ventricular rate in atrial fibrillation and atrial flutter is a function both of the electrophysiological properties of the atrioventricular pathway and of the atrial arrhythmia itself. ${ }^{3-5}$ Previous reports have related electrophysiological properties at rest (functional and effective refractory periods) determined by programmed electrical stimulation to the ventricular rate in atrial fibrillation in patients with the Wolff-Parkinson-White syndrome ${ }^{4}$; less attention has been paid to the more widely available technique of continuous incre-

* This work was supported by a grant from the British Heart Foundation.

† Present address: Cardiac Department, Guy's Hospital, London SE1. mental atrial pacing. ${ }^{26} \mathrm{We}$ have examined the role of atrial pacing in the assessment of different types of atrioventricular pathways in order to assess the ventricular response and to detect those at risk from rapid ventricular rates during atrial fibrillation.

Patients with three types of atrioventricular pathway have been studied: (1) those with conductidn exclusively through the atrioventricular node; (2) those in whom conduction occurred across both an accessory atrioventricular pathway and the atrioventricular node (Wolff-Parkinson-White syndrome); and (3) patients with an atriofascicular bypass tract that could function anterogradely and who had paroxysmal reciprocating atrioventricular tachycardia. ${ }^{78} \mathrm{We}$ also included in the third group patients in whom re-entrant tachycardia could not be initiated but in whom there was a single anterogradely conducting pathway that could transmit impulses more rapidly and at higher rates (above 200 a minute) than would be expected for a normal atrioventricular node. ${ }^{9}$ 
The knowledge of how the ventricles will respond, should atrial fibrillation develop, may be clinically and therapeutically decisive. We have therefore compared the value of the electrophysiological variables derived from incremental atrial pacing with the findings on the surface electrocardiogram during atrial fibrillation.

\section{Subjects and methods}

Fifty-six patients (41 men, 15 women) aged 21 to 72 years (mean 37 years) were studied using electrophysiological methods previously described. ${ }^{6}$ Written consent was obtained from all of them after careful explanation of the purpose of the study, and they were studied in the fasting state without premedication. Pacing wires (USCI no. 6 bipolar) were placed high in the right atrium, opposite the bundle of His, in the right ventricle, and in the coronary sinus (the latter to record and pace from the left atrium and, where possible, the left ventricle).

The functional refractory period (FRP) and effective refractory period (ERP) were measured with the extrastimulus test at physiological heart rates. ${ }^{10}$ Measurements of the RR intervals during atrial fibrillation were made from the standard electrocardiogram recorded during the electrophysiological study. The shortest $R R$ interval throughout the period of the arrhythmia was noted and the mean RR interval calculated. Continuous incremental atrial pacing was performed, from the right atrium or from a site as close as possible to the atrial insertion of the accessory pathway in patients with Wolff-Parkinson-White syndrome, to the point of second degree atrioventricular block. The cycle lengths were measured during $1: 1$ atrioventricular conduction, and the shortest atrial cycle length (pre-Wenckebach cycle length) and shortest RR interval were noted. This maximum rate of pacing was maintained for at least 30 seconds so that the effects of altered cardiovascular reflexes, such as occur during induced or spontaneous tachycardia, ${ }^{11}$ were established. Of 45 patients in whom atrial fibrillation occurred during the study, conduction was entirely through the atrioventricular node in 15, and through an accessory pathway with variable degrees of conduction through the atrioventricular node in 18 . In the remaining 12 there was rapid conduction through an atriofascicular bypass tract ${ }^{12}$ or rapidly conducting atrioventricular node. ${ }^{9}$ In 11 other patients in whom atrial flutter occurred during the investigation the mean $R R$ intervals were measured. Statistical correlations were performed using a linear regression analysis and unpaired Student's $\mathbf{t}$ tests.

\section{Results}

Table 1 shows the shortest and mean RR intervals during atrial fibrillation and the effective refractory period, functional refractory period, shortest $R R$ interval, and pre-Wenckebach cycle length in the 15 patients with isolated normal atrioventricular nodal conduction. There was a significant correlation $(p<0.01)$ with relatively little scatter $(r>0.75)$ between the shortest $R R$ and mean $R R$ measured during atrial fibrillation and the functional refractory period, shortest RR, and pre-Wenckebach cycle length. The effective refractory period could not be measured in eight patients because of atrial refractoriness; in one the test was not performed.

Table $1 R R$ intervals (ms) measured during atrial fibrillation and effective refractory period (ERP), functional refractory period (FRP), shortest $R R$ ( $S R R$ ), and pre-Wenckebach cycle length (PWCL) (ms) measured during electrophysiological investigation in 15 patients with conduction through atrioventricular node

\begin{tabular}{|c|c|c|c|c|c|c|}
\hline \multirow{2}{*}{$\begin{array}{l}\text { Case } \\
\text { no. }\end{array}$} & \multicolumn{2}{|c|}{$\begin{array}{l}\text { Atrial fibrillation } \\
\text { intervals }\end{array}$} & \multicolumn{4}{|c|}{ Electrophysiological data } \\
\hline & $\begin{array}{l}\text { Shortest } \\
R R\end{array}$ & $\begin{array}{l}\text { Mean } \\
R R\end{array}$ & $E R P$ & $F R P$ & $S R R$ & PWCL \\
\hline $\begin{array}{r}1 \\
2 \\
3 \\
4 \\
5 \\
6 \\
7 \\
78 \\
9 \\
10 \\
11 \\
12 \\
13 \\
14 \\
15\end{array}$ & $\begin{array}{l}300 \\
320 \\
380 \\
400 \\
320 \\
400 \\
420 \\
560 \\
400 \\
350 \\
370 \\
430 \\
440 \\
460 \\
315\end{array}$ & $\begin{array}{l}400 \\
.375 \\
528 \\
533 \\
416 \\
570 \\
524 \\
750 \\
594 \\
480 \\
485 \\
666 \\
500 \\
666 \\
395\end{array}$ & $\begin{array}{l}255 \\
t \\
t \\
t \\
400 \\
t \\
t \\
380 \\
\star \\
t \\
t \\
350 \\
315 \\
t \\
345\end{array}$ & $\begin{array}{l}320 \\
375 \\
400 \\
400 \\
270 \\
420 \\
420 \\
490 \\
\star \\
370 \\
400 \\
420 \\
425 \\
440 \\
380\end{array}$ & $\begin{array}{l}310 \\
320 \\
400 \\
390 \\
345 \\
400 \\
375 \\
485 \\
425 \\
345 \\
340 \\
360 \\
405 \\
450 \\
320\end{array}$ & $\begin{array}{l}300 \\
305 \\
380 \\
370 \\
320 \\
390 \\
360 \\
440 \\
425 \\
330 \\
330 \\
350 \\
395 \\
410 \\
305\end{array}$ \\
\hline
\end{tabular}

$\star$ Test not performed.

t This variable could not be measured because of atrial refractoriness.

The studies in the 18 patients with the WolffParkinson-White syndrome (Table 2) disclosed a N significant correlation between the shortest and mean RR intervals during atrial fibrillation and the shortest $R R$ and pre-Wenckebach cycle length $(p<0.01 ; r \geqslant 0.75)$. No such correlation was found, however, between the ventricular rate in atrial $c$ fibrillation and the functional and effective refractory periods $(p>0.05 ; r<0.75)$. The relation? between one electrophysiological measurement during incremental atrial pacing, the shortest $R R$ interval, and that interval during atrial fibrillation in these two groups of atrioventricular pathways is shown in the Fig. 
Table $2 R R$ intervals (ms) measured during atrial fibrillation and effective refractory period (ERP), functional refractory period (FRP), shortest $R R(S R R)$, and pre-Wenckebach cycle length (PWCL) (ms) measured during electrophysiological investigation in 18 patients with conduction through accessory pathway (Wolf-Parkinson-White syndrome)

\begin{tabular}{|c|c|c|c|c|c|c|}
\hline \multirow{2}{*}{$\begin{array}{l}\text { Case } \\
\text { no. }\end{array}$} & \multicolumn{2}{|c|}{$\begin{array}{l}\text { Atrial fibrillation } \\
\text { intervals }\end{array}$} & \multicolumn{4}{|c|}{ Electrophysiological data } \\
\hline & $\begin{array}{l}\text { Shortest } \\
R R\end{array}$ & $\begin{array}{l}\text { Mean } \\
R R\end{array}$ & $E R P$ & $F R P$ & $S R R$ & $P W C L$ \\
\hline $\begin{array}{l}16 \\
17 \\
18 \\
19 \\
20 \\
21 \\
22 \\
23 \\
24 \\
25 \\
26 \\
27 \\
28 \\
29 \\
30 \\
31 \\
32 \\
33\end{array}$ & $\begin{array}{l}240 \\
230 \\
230 \\
275 \\
240 \\
170 \\
270 \\
195 \\
350 \\
220 \\
270 \\
310 \\
210 \\
400 \\
255 \\
250 \\
220 \\
240\end{array}$ & $\begin{array}{l}342 \\
321 \\
316 \\
375 \\
316 \\
260 \\
380 \\
235 \\
375 \\
313 \\
334 \\
625 \\
305 \\
650 \\
435 \\
344 \\
342 \\
412\end{array}$ & $\begin{array}{l}300 \\
320 \\
t \\
t \\
270 \\
250 \\
t \\
265 \\
280 \\
250 \\
280 \\
305 \\
230 \\
t \\
300 \\
310 \\
260 \\
280\end{array}$ & $\begin{array}{l}310 \\
330 \\
t \\
t \\
270 \\
250 \\
t \\
270 \\
290 \\
255 \\
280 \\
320 \\
270 \\
\dagger \\
310 \\
320 \\
280 \\
295\end{array}$ & $\begin{array}{l}280 \\
255 \\
270 \\
265 \\
\star \\
\star \\
240 \\
215 \\
270 \\
245 \\
\star \\
365 \\
190 \\
530 \\
\star \\
\star \\
\star \\
380\end{array}$ & $\begin{array}{l}270 \\
240 \\
265 \\
260 \\
\star \\
\star \\
240 \\
215 \\
265 \\
220 \\
\star \\
365 \\
180 \\
505 \\
\star \\
\star \\
\star \\
380\end{array}$ \\
\hline
\end{tabular}

* Not obtained because of the initiation of atrial fibrillation + This variable could not be measured because of atrial refractoriness.

Corresponding studies in 12 patients with an atriofascicular bypass (or a rapidly conducting atrioventricular node) showed no significant correlation between the ventricular rate in atrial fibrillation and the electrophysiological indices $(p>0.05 ; r<0.75)$ (Table 3). The mean ventricular rate (160 a minute) during atrial fibrillation, however, was significantly faster in this group of patients than in those in whom conduction was only through the atrioventricular node (114 a minute) (p<0.01).

In atrial flutter (11 patients) (Table 4) there was no correlation between the mean $R R$ interval and the electrophysiological indices $(p>0.05 ; r<0.75)$.

\section{Discussion}

The ventricular response in atrial fibrillation showed a positive correlation with electrophysiological variables in two groups, those with pure atrioventricular nodal conduction, and those with the Wolff-Parkinson-White syndrome.

In the patients with conduction through the atrioventricular node alone there was a statistically significant correlation between the functional refractory period, the pre-Wenckebach cycle length, and the shortest $R R$ interval during atrial pacing, and the shortest and mean $R R$ intervals during atrial fibrillation. Atrial refractoriness prevented determination of the effective refractory period in too many patients to permit useful statistical analysis.

In the patients with Wolff-Parkinson-White syndrome a significant correlation was found between the pre-Wenckebach cycle length and the shortest $R R$ interval during atrial pacing, and the

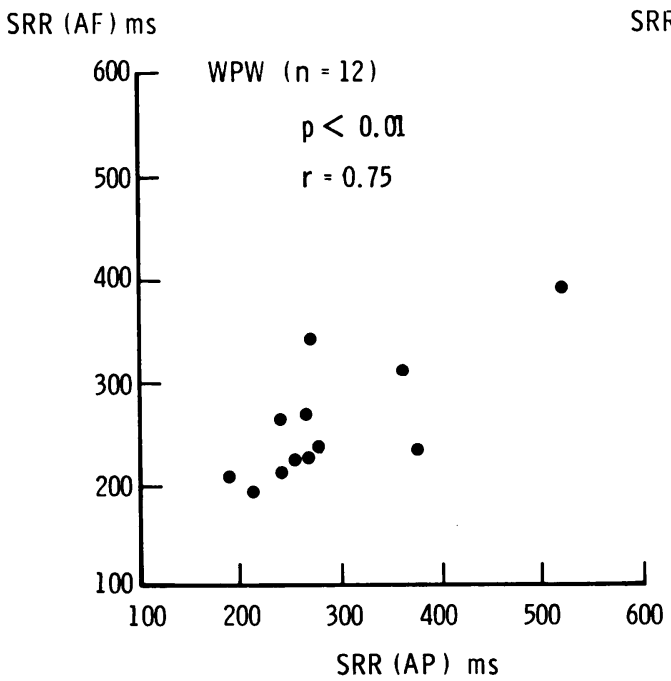

SRR (AF) ms

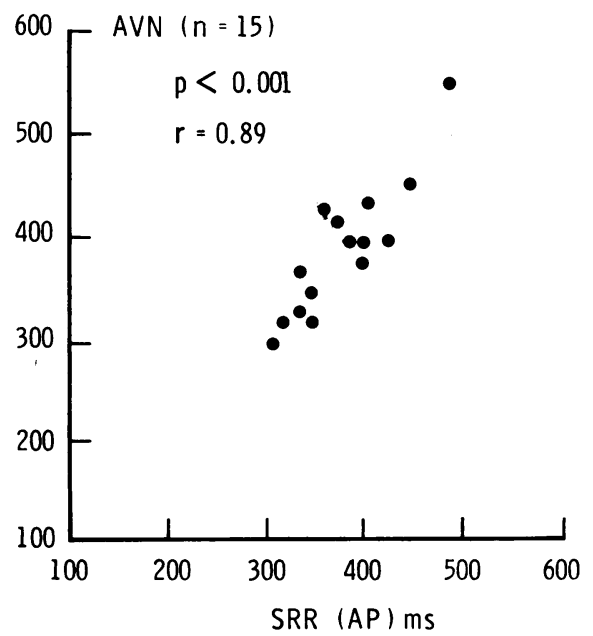

Fig. The relation between the shortest $R R$ interval (ms) during atrial fibrillation ( $S R R$ ( $A F$ )) and the shortest $R R$ interval (ms) during incremental atrial pacing ( $S R R$ ( $A P)$ ) in 12 patients with Wolff-Parkinson-White (WPW) syndrome and 15 patients with atrioventricular nodal conduction (AVN). 
mean and shortest $R R$ interval during atrial fibrillation. We could not confirm a significant correlation between the effective refractory period and functional refractory period of the accessory pathways and the ventricular rate in atrial fibrillation. ${ }^{4}$

Whereas electrophysiological measurements of refractory periods of atrioventricular pathwaysfunctional and effective-represent the ability of that pathway to conduct during the resting state, incremental pacing involves a dynamic element. As the heart rate increases, physiological responses, predominantly alteration in autonomic tone secondary to haemodynamic changes, may themselves influence the conducting system and affect its functional behaviour. ${ }^{11}$ Because the heart rate increases in atrial fibrillation a better correlation may exist between the electrophysiological properties during dynamic testing and the ventricular response in atrial fibrillation. While there are electrophysiological changes in atrioventricular nodal conduction caused by altered haemodynamic circumstances, the relation in patients with accessory pathways is less clear.

Continuous incremental atrial pacing may more closely resemble atrial fibrillation in that impulses constantly depolarise cells in the atrioventricular pathway at various stages of recovery. There is, however, a difference in the mean power and direction of the atrial wave front in atrial fibrillation, and the random nature of the impulse permits inhibition, summation, concealed conduction, and local re-entry to have constantly varying effects. ${ }^{13}$

Table $3 R R$ intervals ( $m s$ ) measured during atrial fibrillation and effective refractory period (ERP), functional refractory period (FRP), shortest RR (SRR), and pre-Wenckebach cycle length (PWCL) (ms) measured during electrophysiological investigation in 12 patients with conduction through atriofascicular bypass tract or rapidly conducting atrioventricular node

\begin{tabular}{|c|c|c|c|c|c|c|}
\hline \multirow{2}{*}{$\begin{array}{l}\text { Case } \\
\text { no. }\end{array}$} & \multicolumn{2}{|c|}{$\begin{array}{l}\text { Atrial fibrillation } \\
\text { intervals }\end{array}$} & \multicolumn{4}{|c|}{ Electrophysiological data } \\
\hline & $\begin{array}{l}\text { Shortest } \\
R R\end{array}$ & $\begin{array}{l}\text { Mean } \\
R R\end{array}$ & $E R P$ & $F R P$ & $S R R$ & $P W C L$ \\
\hline $\begin{array}{l}34 \\
35 \\
36 \\
37 \\
38 \\
39 \\
40 \\
41 \\
42 \\
43 \\
44 \\
45\end{array}$ & $\begin{array}{l}285 \\
300 \\
280 \\
270 \\
235 \\
230 \\
255 \\
230 \\
260 \\
280 \\
295 \\
440\end{array}$ & $\begin{array}{l}325 \\
370 \\
418 \\
354 \\
286 \\
300 \\
375 \\
308 \\
343 \\
387 \\
375 \\
631\end{array}$ & $\begin{array}{l}240 \\
t \\
t \\
t \\
t \\
t \\
t \\
t \\
t \\
t \\
t \\
t\end{array}$ & $\begin{array}{l}270 \\
t \\
310 \\
355 \\
310 \\
330 \\
310 \\
295 \\
320 \\
440 \\
345 \\
370\end{array}$ & $\begin{array}{l}240 \\
280 \\
305 \\
260 \\
240 \\
\star \\
245 \\
\star \\
280 \\
280 \\
290 \\
290\end{array}$ & $\begin{array}{l}200 \\
250 \\
270 \\
255 \\
230 \\
\star \\
240 \\
\star \\
270 \\
260 \\
280 \\
260\end{array}$ \\
\hline
\end{tabular}

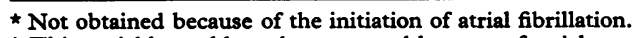
t This variable could not be measured because of atrial refractoriness.
Table 4 Mean RR interval (ms) measured during atrial flutter and effective refractory period (ERP), functional refractory period (FRP), shortest $R R$ ( $S R R$ ), and pre-Wenckebach cycle length (PWCL) (ms) measured during electrophysiological study in 11 patients with conduction through atrioventricular node

\begin{tabular}{|c|c|c|c|c|c|}
\hline \multirow{2}{*}{ Case no. } & \multirow{2}{*}{$\frac{\text { Atrial flutter }}{\text { Mean }}$} & \multicolumn{4}{|c|}{ Electrophysiological data } \\
\hline & & $E R P$ & $F R P$ & $S R R$ & $P W C L$ \\
\hline 46 & 380 & 255 & 320 & 275 & 300 \\
\hline 47 & 414 & $t$ & 375 & 320 & 305 \\
\hline 48 & 400 & $\star$ & $\star$ & 315 & 300 \\
\hline 49 & 420 & $t$ & 260 & 345 & 345 \\
\hline 50 & 428 & $t$ & 330 & 280 & 250 \\
\hline 51 & 390 & $t$ & 340 & 280 & 265 \\
\hline 52 & 395 & $t$ & 310 & 305 & 270 \\
\hline 53 & 370 & $t$ & 355 & 275 & 275 \\
\hline 54 & 431 & $\star$ & $\star$ & 265 & 235 \\
\hline 55 & 400 & $t$ & 370 & 345 & 330 \\
\hline 56 & 260 & $t$ & 270 & 235 & 230 \\
\hline
\end{tabular}

$\star$ Test not performed.

+ This variable could not be measured because of atrial refractoriness.

In the group of patients with atriofascicular bypass tracts (or rapidly conducting atrioventricular nodes) no consistent relation could be found. This small group was by definition heterogeneous. In those patients with atriofascicular bypass tracts the functional and anatomical proximity of the atrioventricular pathways, using the His-Purkinje system as the final common pathway, may allow concealed and decremental conduction to have a greater influence on the ventricular rate in atrial fibrillation than in patients with accessory atrioventricular pathways (the Wolff-Parkinson-White syndrome). In this group, however, the mean ventricular rate in atrial fibrillation was much higher (160 a minute) than in the patients with normal atrioventricular nodal conduction (114 a minute), and almost identical to the rate in those patients with the Wolff-Parkinson-White syndrome (161 a minute). Control of the ventricular rate in atrial fibrillation with atrioventricular nodal blocking drugs may be less effective, an aspect that we are currently exploring.

When considering the clinical symptoms of the patients, these may be interpreted in the light of the expected ventricular rate during atrial fibrillation derived from the electrophysiological data and without inducing the arrhythmia. Atrial fibrillation during electrophysiological study, while confirming the ventricular response, is undesirable if it persists, as it is uncertain whether further electrophysiological assessment after direct current cardioversion is reliable. The maintenance of sinus rhythm allows antiarrhythmic drugs to be given, their effects on atrioventricular conduction to be tested, and information to be obtained that may be useful in 
subsequent oral prophylaxis. ${ }^{14}$ An equally practical point arises when there is a history of syncope in a patient in whom arrhythmia has been suspected but not documented: incremental atrial pacing will disclose the potential ventricular response.

The ability to predict the relevant electrophysiological properties from the simple and widely available technique of incremental atrial pacing offers an additional and perhaps more reliable method for the recognition of the ventricular response, though the induction of atrial fibrillation remains the definitive test.

\section{References}

1 Dreifus LS, Haiat R, Watanabe Y, Arriaga J, Reitman NC. Ventricular fibrillation: a possible mechanism of sudden death in patients with WolffParkinson-White syndrome. Circulation 1971; 43: 520-7.

2 Klein GJ, Bashore TM, Sellers TD, Pritchett ELC, Smith WM, Gallagher JJ. Ventricular fibrillation in the Wolff-Parkinson-White syndrome. $N$ Engl $\mathcal{F}$ Med 1979 ; 301 : 1080-5.

3 Moore EN, Spear JF, Boineau JP. Electrophysiological studies on preexcitation in the dog using an electronically simulated atrioventricular bypass pathway. Circ Res 1972; 31: 174-85.

4 Wellens HJ, Durrer D. Wolff-Parkinson-White syndrome and atrial fibrillation. Relation between refractory period of accessory pathway and ventricular rate during atrial fibrillation. Am $\mathcal{f}$ Cardiol 1974; 34: 777-82.

5 Castellanos A Jr, Myerburg RJ, Craparo K, Befeler $B$, Agha AS. Factors regulating ventricular rates during atrial flutter and fibrillation in pre-excitation (Wolff-Parkinson-White) syndrome. $\mathrm{Br}$ Heart $\mathcal{f}$ $1973 ; 35$ : 811-6.
6 Curry PVL. Fundamentals of arrhythmias: modern methods of investigation. In: Krikler DM, Goodwin JF, eds. Cardiac arrhythmias-the modern electrophysiological approach. London: Saunders, 1975: 38-80.

7 Mendez C, Moe GK. Demonstration of a dual A-V nodal conduction system in the isolated rabbit heart. Circ Res 1966; 19: 378-93.

8 Barold SS, Coumel P. Mechanisms of atrioventricular junctional tachycardia. Role of reentry and concealed accessory bypass tracts. Am $\mathcal{f}$ Cardiol 1977 ; 39: 97106.

9 Gallagher JJ, Sealy WC, Kasell J, Wallace AG. Multiple accessory pathways in patients with the preexcitation syndrome. Circulation 1976; 54: 571-91.

10 Denes P, Wu D, Dhingra R, Pietras RJ, Rosen KM. The effects of cycle length on cardiac refractory periods in man. Circulation 1974; 49: 32-41.

11 Curry PVL, Rowland E, Fox KM, Krikler DM. The relationship between posfure, blood pressure and the electrophysiological properties in patients with paroxysmal supraventricular tachycardia. Arch Mal Coeur 1978; 71: 293-9.

12 Brechenmacher C. Atrio-His bundle tracts. Br Heart f 1975; 37: 853-5.

13 Konishi T, Matsuyama E. Effect of changes in inputs to atrioventricular node on AV conduction. Fap Circ f 1976; 40: 1392-400.

14 Rowland E, Krikler DM: Electrophysiological assessment of amiodarone in treatment of resistant supraventricular arrhythmias. Br Heart $\mathcal{f} 1980$; 44: 82-90.

Requests for reprints to Dr Dennis Krikler, Division of Cardiovascular Disease, Royal Postgraduate Medical School, Hammersmith Hospital, Du Cane Road, London W12 0HS. 